\title{
PENGUKURAN SALINITAS AIR SUNGAI TERCEMAR LIMBAH CAIR MENGGUNAKAN SENSOR KONDUKTIVITAS
}

\author{
Novita Fitriani ${ }^{\mathrm{a})}$, Widyaningrum Indrasari ${ }^{\mathrm{b})}$, Umiatin $^{\mathrm{c})}$ \\ Program Studi Fisika, Fakultas Matematika Ilmu Pengetahuan Alam, Universitas Negeri Jakarta, Jl. \\ Rawamangun Muka, Jakarta Timur 13220
}

Email: ${ }^{a)}$ novitafitriani51@gmail.com, ${ }^{\text {b) }}$ widyafisikaunj@gmail.com, ${ }^{\mathrm{c}}$ ummiatin@yahoo.com

\begin{abstract}
Abstrak
Seiring dengan pertambahan penduduk dan pembangunan ekonomi, jenis dan kuantitas limbah cair semakin besar. Di lain pihak kebutuhan air bersih juga semakin meningkat. Hal ini tidak diimbangi dengan kondisi kualitas air yang semakin menurun. Salah satu syarat air yang dapat dimanfaatkan untuk kebutuhan air bersih adalah air yang memiliki nilai salinitas $\leq 0.5$ ppt. Salinitas menggambarkan kadar garam yang terlarut dalam air. Pada penelitian ini dirancang pengukuran salinitas air tercemar limbah cair menggunakan sensor konduktivitas dan Arduino UNO sebagai sistem kontrol. Penelitian ini bertujuan untuk mengetahui apakah air sungai yang diuji layak dijadikan sumber air bersih berdasarkan parameter salinitas. Hasil karakterisasi sensor menunjukkan sensitivitas sensor sebesar $0.4152 \mathrm{mV} / \mathrm{ppt}$ dengan kesalahan relatif maksimum sebesar 5.26\%. Pada pengujian salinitas air sungai, diambil sampel yang berasal dari wilayah Cipinang, Banjir Kanal Timur (BKT), Galur, dan Bekasi. Berdasarkan hasil pengujian salinitas, sampel air sungai yang diambil dari keempat wilayah yang berbeda memenuhi syarat salinitas air bersih yaitu $\leq 0.5 \mathrm{ppt}$ sehingga layak dijadikan sumber air bersih.
\end{abstract}

Kata-kata kunci: Limbah cair, salinitas, konduktivitas, sensitivitas.

\begin{abstract}
Along with population growth and economic development, the type and quantity of liquid waste is getting bigger. On the other hand, the need for clean water is also increasing. This is not balanced with the condition of declining water quality. One of the requirements for water that can be used for clean water needs is water that has a salinity value of $\leq 0.5 \mathrm{ppt}$. Salinity describes the salt content dissolved in water. In this study, the measurement of salinity of polluted water using a conductivity sensor and Arduino UNO as a control system was designed. This study aims to determine whether river water tested is suitable as a source of clean water based on salinity parameters. The sensor characterization results showed sensor sensitivity of $0.4152 \mathrm{mV} / \mathrm{ppt}$ with a maximum relative error of $5.26 \%$. In testing the river water salinity, samples were taken from the Cipinang area, Banjir Kanal Timur (BKT), Galur, and Bekasi. Based on the results of salinity testing, river water samples taken from the four different regions meet the salinity requirements of clean water, namely $\leq 0.5 \mathrm{ppt}$ so that they are suitable as a source of clean water.
\end{abstract}

Keywords: Liquid waste, salinity, conductivity sensor, sensitivity. 


\section{PENDAHULUAN}

Dewasa ini seiring berkembangnya zaman jumlah dan kuantitas limbah khususnya limbah cair semakin meningkat. Peningkatan tersebut disebabkan oleh kepadatan penduduk, pembangunan ekonomi, penggunaan alat industri, dan lain sebagainya. Namun kondisi tersebut tidak diimbangi dengan jumlah ketersediaan air yang ada. Menurut Kementerian Perencanaan Pembangunan Nasional/Badan Perencana Pembangunan Nasional (Kementerian PPN/Bappenas) pada tahun 2015, ketersediaan air/kapita/tahun di Pulau Jawa sebesar $1.750 \mathrm{~m}^{3} / \mathrm{kapita} /$ tahun. Data tersebut dibawah standar kecukupan ketersediaan air yaitu $2000 \mathrm{~m}^{3} / \mathrm{kapita} / \operatorname{tahun[1].~Tercemarnya~sungai~khususnya~}$ oleh limbah cair dapat menurunkan kualitas air sehingga diperlukan suatu pengujian untuk mengetahui apakah air sungai yang tercemar limbah cair layak dijadikan sumber air bersih.

Salah satu parameter pengujian kualitas air adalah salinitas. Salinitas menggambarkan kadar garam yang terlarut dalam air. Salah satu syarat air yang dapat dimanfaatkan sebagai air bersih adalah air yang memiliki nilai salinitas $\leq 0.5 \mathrm{ppt}[2]$. Air yang memiliki salinitas tinggi $(\geq 0.5 \mathrm{ppt})$ dapat menyebabkan gangguan kesehatan seperti dehidrasi, diare, dan penyakit kulit[3].

Namun alat uji salinitas air hanya dimiliki oleh pihak tertentu, sehingga menyulitkan penggunaannya untuk pengukuran sehari-hari, maka diperlukanlah pengembangan alat ukur salinitas air tercemar limbah yang portable. Pada penelitian ini dirancang pengukuran salinitas air tercemar limbah menggunakan sensor konduktivitas dan Arduino UNO sebagai sistem kontrolnya. Untuk mengetahui tingkat akurasi sensor yang digunakan, maka dilakukan karakterisasi dengan membandingkan nilai keluaran sensor dengan alat uji salinometer tipe SA-287 yang ada pada laboraturium. Nantinya alat uji salinometer tipe SA-287 akan dijadikan acuan dalam pembuatan sistem ini.

\section{METODOLOGI}

Pengukuran salinitas ini menggunakan sensor konduktivitas. Karakterisasi sensor konduktivitas dilakukan dengan cara memasukan bagian sensor tersebut kedalam larutan agar dapat dilihat seberapa besar nilai keluarannya. Tujuan karakterisasi tersebut adalah untuk menentukan sensitivitas, rentang pengukuran, dan kesalahan relatif sensor. Sensitivitas merupakan rasio dari perubahan sinyal keluaran terhadap sinyal masukan dapat dituliskan dengan menggunakan persamaan sebagai berikut[4]:

$$
\text { Sensitivitas }=\frac{\Delta y}{\Delta x}
$$

Dengan $\Delta \boldsymbol{x}$ adalah perubahan nilai tegangan pada sensor yang digunakan, dan $\boldsymbol{\Delta y}$ adalah perubahan nilai salinitas yang telah diuji menggunakan alat laboratorium yaitu salinometer tipe SA287. Rentang pengukuran merupakan hasil pengukuran maksimum dan minimum yang masih terbaca oleh sensor. Sedangkan kesalahan relatif sensor merupakan persentasi perbandingan nilai pengukuran dengan nilai sebenarnya dengan persamaan sebagai berikut [4]:

$$
\text { Error }(\%)=\frac{\mid \text { PS-PL } \mid}{\text { PL }} \times 100 \%
$$

Dengan PS adalah pembacaan nilai salinitas pada sensor yang digunakan, dan PL adalah pembacaan nilai salinitas yang telah diuji menggunakan alat laboratorium. 


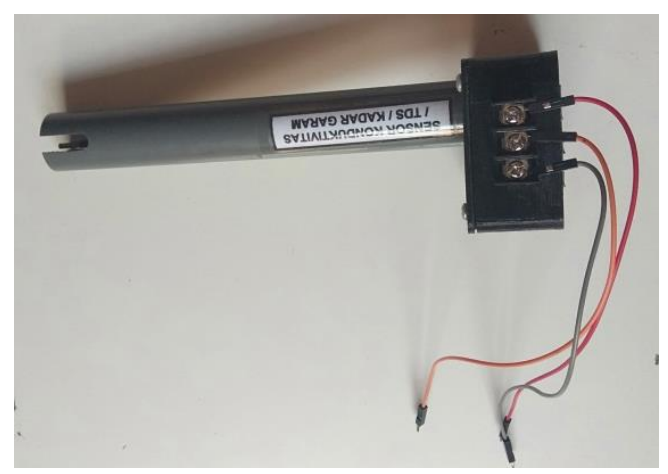

GAMBAR 1. Sensor konduktivitas

Jenis sensor yang digunakan pada pengukuran salinitas air

Kalibrasi dilakukan dengan menggunakan 13 sampel larutan air sungai wilayah Bekasi yang masing-masing sebanyak $1000 \mathrm{~mL}$. Masing-masing sampel ditambahkan garam dengan penambahan massa garam sebanyak $50 \mathrm{mg}$. Variasi massa garam yang ditambahkan pada masing-masing sampel dimulai dari $50 \mathrm{mg}$ hingga $600 \mathrm{mg}$ dan satu sampel tanpa penambahan garam.

Kemudian untuk pengujiannya digunakan empat sampel air sungai yang berasal dari wilayah Cipinang, BKT, Galur, dan Bekasi yang masing-masing sebanyak $100 \mathrm{~mL}$. Hasil pengujian tersebut dilanjutkan dengan melakukan pengukuran nilai salinitas masing-masing sampel.

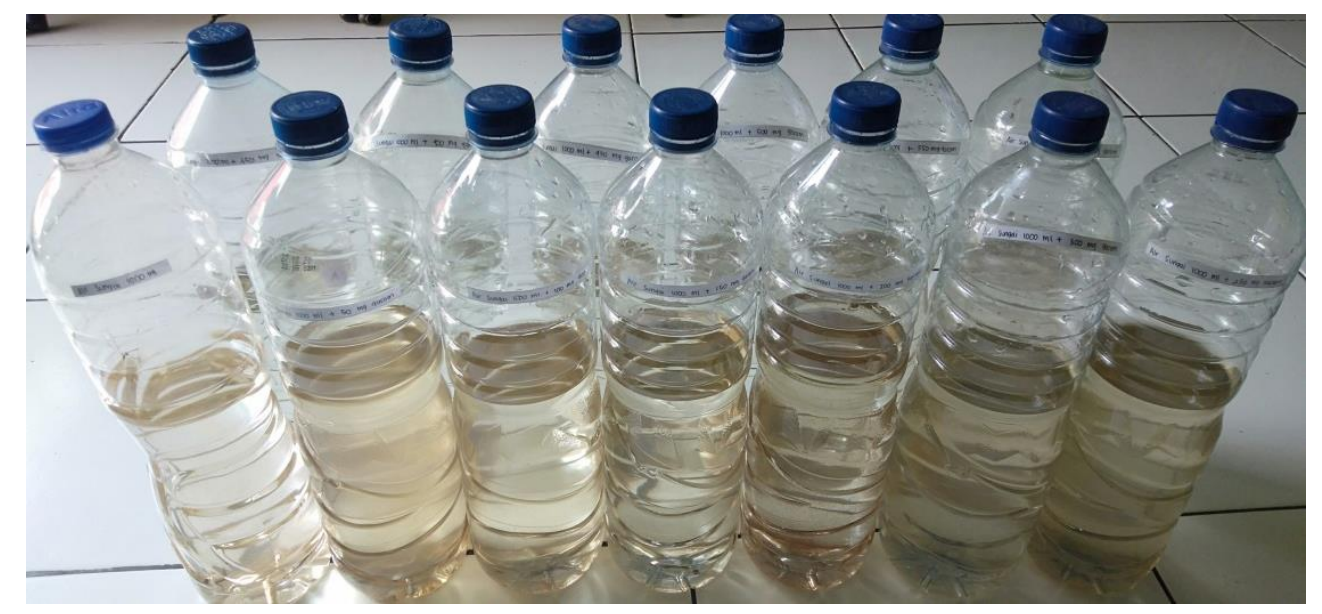

GAMBAR 2. Sampel larutan kalibrasi

Sampel larutan kalibrasi yang terdiri atas $1000 \mathrm{~mL}$ air sungai wilayah Bekasi dan garam dengan variasi penambahan massa garam sebesar $50 \mathrm{mg}$

\section{HASIL DAN PEMBAHASAN}

\section{a. Sensor Konduktivitas}

Karakterisasi sensor konduktivitas dilakukan dengan membandingkan hasil tegangan keluaran pada sensor dengan pengukuran sampel salinitas pada laboratorium. Hasil pengukuran dapat dilihat pada TABEL 1 dan grafik pada GAMBAR 3. 
TABEL 1. Data nilai salinitas laboraturium dan salinitas sensor

\begin{tabular}{cccc}
\hline No. Sampel & $\begin{array}{c}\text { Salinitas } \\
\text { Laboraturium (ppt) }\end{array}$ & Salinitas Sensor (ppt) & $\begin{array}{c}\text { Kesalahan Relatif } \\
(\%)\end{array}$ \\
\hline 1 & 0.201 & 0.203 & 0.995 \\
2 & 0.247 & 0.260 & 5.263 \\
3 & 0.294 & 0.303 & 3.061 \\
4 & 0.351 & 0.353 & 0.569 \\
5 & 0.407 & 0.394 & 3.194 \\
6 & 0.444 & 0.433 & 2.477 \\
7 & 0.493 & 0.483 & 2.028 \\
8 & 0.533 & 0.514 & 3.565 \\
9 & 0.563 & 0.555 & 1.421 \\
10 & 0.591 & 0.586 & 0.846 \\
11 & 0.635 & 0.643 & 1.259 \\
12 & 0.676 & 0.684 & 1.183 \\
13 & 0.709 & 0.725 & 2.256 \\
\hline
\end{tabular}

Pada TABEL 1 di atas, nilai kesalahan relatif pengukuran pada sensor konduktivitas diperoleh dengan menggunakan persamaan (1). Nilai kesalahan relatif pengukuran maksimum yaitu pada sampel nomer 2 sebesar $5.26 \%$. Sensor konduktivitas ini bekerja baik pada rentang pengukuran antara $0.203-0.725$ ppt. Hubungan antara nilai tegangan sensor dan hasil pengujian salinitas pada laboraturium dapat dilihat pada GAMBAR 3.

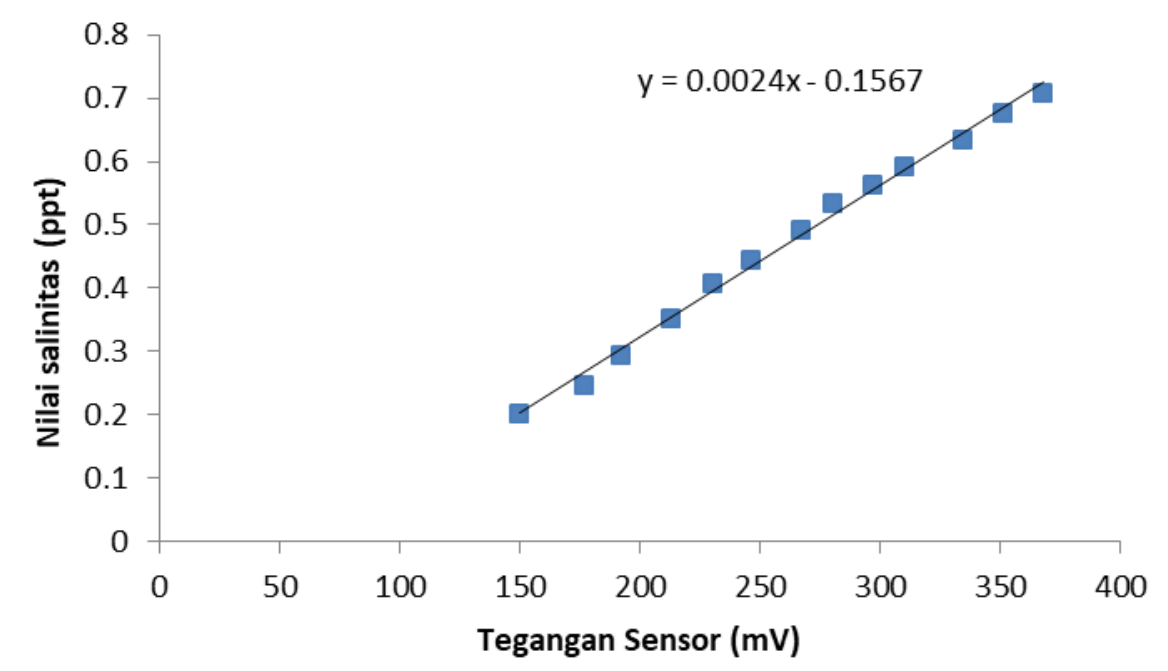

GAMBAR 3. Grafik hubungan tegangan keluaran sensor terhadap hasil pengujian salinitas di laboraturim

Berdasarkan grafik diatas, diperoleh invers persamaan fungsi transfer yang memenuhi yaitu :

$$
y=415.2 x-66.461
$$

Dengan $\mathrm{x}$ berupa tegangan sensor dalam miliVolt dan y merupakan nilai salinitas dalam ppt (part per thousand. Pada persamaan diatas diperoleh nilai sensitivitas sensor konduktivitas yang diperoleh menggunakan persamaan (2) yaitu sebesar $415.2 \mathrm{mV} / \mathrm{ppt}$, dimana untuk setiap perubahan input $1 \mathrm{ppt}$ akan menghasilkan output sebesar $415.2 \mathrm{mV}$ pada sensor.

Grafik pada GAMBAR 3 menunjukkan hubungan yang linear antara nilai salinitaas laboratorium dengan tegangan keluaran sensor. Hal ini menandakan bahwa semakin besar nilai salinitas maka akan semakin besar pula nilai tengangan keluarannya. Kedua elektroda yang diberikan beda potensial menyebabkan ion-ion yang berada dalam air berpisah menjadi kation dan anion. Kation akan bergerak menuju elektroda negatif dan anion akan bergerak menuju eletroda positif. Ionion yang bergerak ini menyebabkan larutan bertindak sebagai konduktor. Semakin besar konsentasi 
garamnya ion-ion yang bergerak akan semakin banyak sehingga semakin besar nilai konduktivitasnya. Nilai konduktivitas berbanding lurus dengan salinitas, semakin besar nilai konduktivitasnya semakin besar nilai salinitas yang dihasilkan [5].

\section{b. Pengujian Sampel}

Pengujian sistem pengukuran salinitas ini dilakukan pada bulan Maret 2019. Pengujian dilakukan dengan membaca hasil keluaran sensor konduktivitas setelah dilakukan kalibrasi. Pada pengujian ini digunakan empat sampel air sungai yang berbeda dengan volume air sebanyak $100 \mathrm{~mL}$.

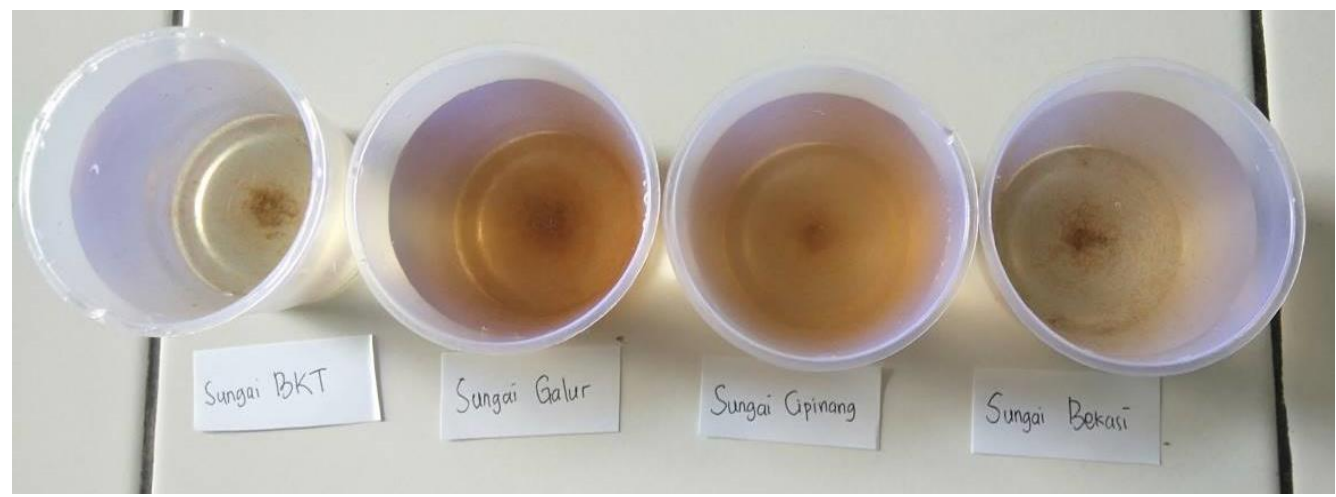

GAMBAR 4. Sampel laruran uji

sampel ini terdiri atas air sungai yang berasal dari BKT, Galur, Cipinang, dan Bekasi

TABEL 2. Daftar sampel larutan uji

\begin{tabular}{ccc}
\hline No. Sampel & Sampel yang di Uji & Nilai Salinitas Sensor (ppt) \\
\hline 1. & Air Sungai wilayah Cipinang & 0.076 \\
2. & Air Sungai wilayah BKT & 0.089 \\
3. & Air Sungai wilayah Galur & 0.349 \\
4. & Air Sungai wilayah Bekasi & 0.203 \\
\hline
\end{tabular}

Berdasarkan hasil tersebut, nilai salinitas air sungai terendah berada pada wilayah Cipinang dan nilai tertinggi berada pada wilayah Galur. Hal ini disebabkan karena pengaruh penguapan dan presipitasi. Nilai salinitas air berpengaruh terhadap tekanan osmotik dimana semakin tinggi nilai salinitas air maka semakin tinggi tekanan osmotiknya[6]. Secara keseluruhan, keempat sampel memenuhi syarat salinitas air bersih yaitu $\leq 0.5$ ppt. Hasil ini menandakan bahwa keempat sampel air sungai tersebut tidak mengandung banyak larutan garam serta larutan mineral di dalamnya sehingga layak dijadikan sumber air bersih berdasarkan parameter salinitas.

\section{SIMPULAN}

Hasil karakterisasi sensor konduktivitas menggunakan mikrokontroler Arduino UNO menunjukan rentang pengukuran sebesar $0.203-0.725 \mathrm{ppt}$, sensitivitas sensor sebesar $415.2 \mathrm{mV} / \mathrm{ppt}$, dan kesalahan relatif pengukuran maksimum yang diperoleh yaitu, sebesar 5.26\%. Setelah dilakukan pengujian terhadap empat sampel air sungai tercemar limbah yaitu sungai Cipinang, BKT, Galur dan Bekasi diperoleh bahwa keempat sampel memenuhi syarat salinitas air bersih yaitu $\leq 0.5$ ppt sehingga layak dijadikan sumber air bersih.

\section{REFERENSI}

[1] Kementrian PPN/Bappenas. 2015. Perencanaan Pembangunan Pertanian dan Pedesaan: Masalah dan Peta Jalan ke Depan. Jakarta: Kementrian PPN/Bappenas. 
[2] Hamuna dkk, B. 2018. Kajian Kualitas Air Laut dan Indeks Pencemaran Berdasarkan Parameter Fisika-Kimia Di Perairan Distrik Depapre, Jayapura. Semarang: Jurnal Ilmu Lingkungan Vol.2 No.2 Hal.35-43.

[3] Rizkiansyah, M. 2016. Analisis Kualitas Air Sumur Gali di Desa Pematang Kuala Kecamatan Teluk Mengkudu Kabupaten Serdang Bedagai. Sumatra Utara: Universitas Negeri Medan.

[4] Fraden, J. 2003. Handbook of Modern Sensor : Physics, Designs, and Applications. California : Advanced Monitors Corporation.

[5] Siltri, dkk, D.M., Yohandri, \& Kamus Z.2015. Pembuatan Alat Ukur Salinitas dan Kekeruhan Air Menggunakan Sensor Elektroda dan LDR. Padang: Jurnal Sainstek Vol.VII No.2 Hal. 126-139.

[6] Widiadmoko, W. 2013. Pemantauan Kualitas Air Secara Fisika dan Kimia di Perairan Teluk Hurun. Bandar Lampung: Balai Besar Pengembangan Budidaya Laut (BBPBL) Lampung.

[7] Kadim,dkk, M.K., Pasisingi N., \& Paramata A.R.2017. Kajian Kualitas Perairan Teluk Gorontalo dengan Menggunakan Metode STORET. Banda Aceh: Jurnal Ilmu-Ilmu Perairan, Pesisir, dan Perikanan Vol.6 No.3 Hal.235-241.

[8] Suparta, dkk, M. 2018. Rancang Bangun Alat Ukur Salinitas dan Suhu Menggunakan Mikrokontroler ATMEGA328P Berbasis Data Logger yang Terintegrasi dengan GPS. Pontianak: Prisma Fisika Vol. Vol.VI No.01 Hal.70-75. 